\title{
DEGRADATION AND MOVEMENT OF TERBUTHYLAZINE IN SOIL
}

\author{
T.K. JAMES ${ }^{1}$, A. RAHMAN ${ }^{1}$, P.T. HOLLAND ${ }^{2}$, \\ D.E. McNAUGHTON ${ }^{2}$ and M. HEIERMANN ${ }^{1}$
}

\author{
${ }^{1}$ AgResearch, Ruakura Research Centre, Private Bag 3123, Hamilton \\ ${ }^{2}$ HortResearch, Ruakura Research Centre, Private Bag 3123, Hamilton
}

\begin{abstract}
The persistence and movement of terbuthylazine was studied in two soils in field experiments. The effects of temperature and soil moisture on degradation were further studied in one soil under controlled environment conditions. In the field, terbuthylazine residues were reduced within 6 months to $1 \%$ - 5\% of that applied with half-lives of 23 and 37 days in a sandy and clay soil respectively. No residues were detected below $10 \mathrm{~cm}$. Temperature had a major effect on degradation while soil water content had very little effect. Under normal conditions of use, terbuthylazine residues should not carry over to the next growing season and are unlikely to contaminate groundwater.
\end{abstract}

Keywords: terbuthylazine, soil residues, persistence, movement, degradation.

\section{INTRODUCTION}

The herbicide terbuthylazine is widely used for pre-emergence or post-emergence control of many grass and broadleaf weeds. In New Zealand terbuthylazine is registered for selective weed control in maize, sweet corn, peas, established lucerne and in forestry. In combination with other herbicides it is used also for pre-emergence weed control in asparagus, apples and kiwifruit. More recently terbuthylazine has replaced the widely used herbicide atrazine in some situations because of its lower water solubility ( $8.5 \mathrm{vs} 33.0 \mathrm{mg} /$ litre) and lower persistence in soil (Rahman and Matthews 1979; Nordmeyer and Pestemer 1995).

The half-life of terbuthylazine in the soil has been reported to vary between 5 and 116 days depending on the soil characteristics and temperature (Sahid and Teoh 1994; Nordmeyer and Pestemer 1995; Dousset et al. 1997). Even within one soil type, the residual activity decreased by $41 \%$ and $54 \%$ as the organic matter level increased from a base level of $9.8 \%$ to $15.5 \%$ and $20.6 \%$ respectively (Rahman and Matthews 1979). Terbuthylazine moves less within the soil profile than atrazine (Bowman 1989) and highest soil residues are usually found in the top soil layer (Barreda et al. 1996). The half-life of terbuthylazine in the soil increased to 144 days at $10^{\circ} \mathrm{C}$ from 68 days at $20^{\circ} \mathrm{C}$ (Dibbern and Pestemer 1992).

There is little published work on the degradation and movement of terbuthylazine in New Zealand soils. As a consequence of its increasing usage in cropping, horticulture and forestry there is a need for information on its fate in our soils. This paper presents results on persistence and movement of terbuthylazine in two soils under field conditions and on rates of degradation in laboratory conditions under different temperature/soil moisture regimes in one soil.

\section{Field trials}

\section{MATERIALS AND METHODS}

Two trials were established on cultivated ground near Hamilton on a Horotiu sandy loam soil ( $61 \%$ sand, $15 \%$ clay, $8.7 \%$ OC, bulk density $0.71 \mathrm{~kg} /$ litre and $\mathrm{pH} 5.4$ ) and a Hamilton clay loam soil (29\% sand, $31 \%$ clay, $4.6 \%$ OC, bulk density $1.07 \mathrm{~kg} /$ litre and pH 5.6) on 20 November 1997. The terbuthylazine (Gardoprim) treatments 
( 1.5 and $3.0 \mathrm{~kg} / \mathrm{ha}$ ) were applied by hand with a $\mathrm{CO}_{2}$ powered sprayer using TeeJet 8003 nozzles at $200 \mathrm{kPa}$ in 300 litres water/ha. The treatments were replicated three times and arranged in a randomised block design at each site. Plot sizes were $3 \times 9 \mathrm{~m}$ on the Horotiu soil and $4 \times 6 \mathrm{~m}$ on the Hamilton soil.

At time of treatment and 7, 14, 21 and 28 days thereafter, two soil samples were collected to $10 \mathrm{~cm}$ depth from each plot using a $7.5 \mathrm{~cm}$ diameter stainless steel soil sampling tube. Soil samples were extracted intact from the sampler on site, divided into $0-5 \mathrm{~cm}$ and $5-10 \mathrm{~cm}$ layers and the respective layers combined and stored at $-20^{\circ} \mathrm{C}$. On days $41,55,84,127$ and 157 , three soil samples were collected with a Humax soil sampler ( $5 \mathrm{~cm}$ diameter) to $25 \mathrm{~cm}$ depth from each plot. These samples were collected directly into clear PVC casings and were immediately frozen. The frozen samples were sawn into $5 \mathrm{~cm}$ layers, their casings removed and the samples cleaned by removing the outer $2 \mathrm{~mm}$ of soil before respective layers from each treatment were combined for extraction and analysis. Rainfall and soil temperature (10 $\mathrm{cm}$ depth) data were collected at both sites.

\section{Controlled environment degradation study}

A bulk sample of the Horotiu sandy loam soil was collected from the field trial site and used for the degradation study. Aliquots of partially dried soil (50 g dry weight) in conical flasks were individually treated after being adjusted to the required soilwater content. The soil was fortified with an aqueous solution $(1 \mathrm{ml})$ of the formulated product ( $214 \mathrm{mg} / \mathrm{litre}$ ), equivalent to the $3.0 \mathrm{~kg} / \mathrm{ha}$ rate used in the field (incorporated to $10 \mathrm{~cm}$ ). Sixteen flasks were maintained at each of the five soil-water content/ temperature combinations, viz. $60 \%$ of maximum water holding capacity (m.w.h.c.) maintained at 10,22 or $30^{\circ} \mathrm{C}$ and $40 \%$ and $80 \%$ of m.w.h.c. maintained at $22^{\circ} \mathrm{C}$. Water was added once a week to bring the flasks up to the pre-determined weight. After 0 , $1,2,4,8,12,16$ and 26 weeks, two flasks were taken from each soil-water content/ temperature combination and stored at $-20^{\circ} \mathrm{C}$ until analysed.

\section{Chemical extraction and analysis}

The defrosted soil samples from the field were thoroughly mixed and passed through a $4 \mathrm{~mm}$ sieve and a sample equivalent to $50 \mathrm{~g}$ dry matter was placed in a 250 $\mathrm{ml}$ flask. All samples were shaken with $100 \mathrm{ml}$ of 70:30 methanol/water for $1 \mathrm{~h}$ and then allowed to stand for $4 \mathrm{~h}$ before a $20 \mathrm{ml}$ aliquot of the supernatant liquid was pipetted off. A surrogate standard, $1 \mathrm{ml}$ of $5 \mu \mathrm{g} / \mathrm{ml}$ atrazine (technical grade), was added to the extract solution. The solution was then extracted three times with dichloromethane $(7,3.5$ and $3.5 \mathrm{ml})$. The combined dichloromethane fraction was evaporated under $\mathrm{N}_{2}$ until dry. The extracts were redissolved in $0.5 \mathrm{ml}$ of methanol and then made up to $1 \mathrm{ml}$ with water.

The analyses were by high performance liquid chromatography (HPLC) using a $15 \mathrm{~cm}$ Prodigy $5 \mu \mathrm{m}$ ODS(3) column held at $35^{\circ} \mathrm{C}$ for separation. The mobile phase was $56: 44$ methanol/water at a flow rate of $1 \mathrm{ml} / \mathrm{min}$. Determination was by UV detector at $230 \mathrm{~nm}$. This system gave a retention time of $9.0 \mathrm{~min}$ for atrazine and 16.9 min for terbuthylazine. The $50 \mu$ injection volume used resulted in a detection limit of $15 \mu \mathrm{g}$ terbuthylazine/kg dry soil.

For the field experiments, standard deviations for the three replicates were calculated and are presented in Table 1. For the laboratory study, data from the duplicate samples were averaged and plotted on a semi-log scale. Minitab was used to calculate the straight line regressions from which the half-lives were calculated.

\section{RESULTS AND DISCUSSION}

The degradation of terbuthylazine was slower in the heavier Hamilton clay loam soil than in the Horotiu sandy loam soil (Table 1). Also the herbicide was slower to move from the top $5 \mathrm{~cm}$ into the $5-10 \mathrm{~cm}$ layer in the clay soil. Whereas in the sandy soil, terbuthylazine was detected in the $5-10 \mathrm{~cm}$ layer 7 days after treatment, none was found in the lower layer until 41 days after treatment in the clay soil. Despite this rapid movement in the sandy soil however, the amount of terbuthylazine found in the deeper layer was similar in both soils. No residues were detected in either soil at the $10-25$ $\mathrm{cm}$ depths. By the last day of sampling, 157 days after treatment, the amount of 
terbuthylazine in the soil was reduced to about $1 \%$ of that applied in the Horotiu sandy loam soil and 5\% in Hamilton clay loam soil.

TABLE 1: Terbuthylazine residues ( $\mu \mathrm{g} / \mathrm{kg}$ dry soil) in two soils each at two depths, and rainfall and soil temperature for the trial period.

\begin{tabular}{|c|c|c|c|c|}
\hline & $1.5 \mathrm{~kg}$ ai $/ \mathrm{ha}$ & $3.0 \mathrm{~kg}$ ai $/ \mathrm{ha}$ & Rain $^{\mathrm{a}}$ & Soil temp ${ }^{a}$ \\
\hline Day & $0-5 \mathrm{~cm} \quad 5-10 \mathrm{~cm}$ & $5-10 \mathrm{~cm}$ & $(\mathrm{~mm})$ & $\left({ }^{\circ} \mathrm{C}\right)$ \\
\hline
\end{tabular}

\begin{tabular}{|c|c|c|}
\hline \multicolumn{3}{|c|}{ Horotiu sandy loam } \\
\hline 0 & $3644 \pm 358^{b}$ & n.d. ${ }^{\mathrm{c}}$ \\
\hline 7 & $1889 \pm 42$ & $43 \pm 17$ \\
\hline 14 & $1609 \pm 116$ & n.d. \\
\hline 21 & $1061 \pm 321$ & n.d. \\
\hline 28 & $662 \pm 234$ & $18 \pm 6$ \\
\hline 41 & $419 \pm 198$ & $23 \pm 40$ \\
\hline 55 & $160 \pm 26$ & n.d. \\
\hline 84 & $73 \pm 35$ & n.d. \\
\hline 127 & $30 \pm 24$ & n.d. \\
\hline 157 & $37 \pm 31$ & n.d. \\
\hline
\end{tabular}

$\begin{array}{ccrc}7524 \pm 885 & \text { n.d. } & 35.6 & 17.4 \\ 2968 \pm 431 & 320 \pm 444 & 5.7 & 18.7 \\ 2994 \pm 488 & 54 \pm 15 & 30.0 & 19.4 \\ 2008 \pm 438 & 25 \pm 6 & 10.6 & 19.5 \\ 1333 \pm 292 & 31 \pm 17 & 20.2 & 21.7 \\ 910 \pm 193 & 27 \pm 47 & 21.9 & 22.0 \\ 214 \pm 97 & \text { n.d. } & 2.5 & 22.1 \\ 167 \pm 182 & 18 \pm 20 & 21.1 & 24.4 \\ 66 \pm 47 & \text { n.d. } & 127.7 & 21.8 \\ 138 \pm 74 & \text { n.d. } & 38.1 & 17.8\end{array}$

Hamilton clay loam

\begin{tabular}{lccclrl}
0 & $2433 \pm 289$ & n.d. & $4883 \pm 480$ & n.d. & 29.2 & 15.0 \\
7 & $2157 \pm 632$ & n.d. & $3441 \pm 156$ & n.d. & 8.6 & 16.1 \\
14 & $1336 \pm 176$ & n.d. & $3292 \pm 328$ & n.d. & 39.8 & 17.6 \\
21 & $1008 \pm 287$ & n.d. & $2207 \pm 98$ & n.d. & 16.7 & 16.8 \\
28 & $779 \pm 279$ & n.d. & $1727 \pm 137$ & n.d. & 37.6 & 20.0 \\
41 & $1028 \pm 398$ & $19 \pm 11$ & $1786 \pm 560$ & $53 \pm 29$ & 12.4 & 19.8 \\
55 & $620 \pm 337$ & $18 \pm 17$ & $1130 \pm 128$ & $53 \pm 21$ & 6.0 & 18.8 \\
84 & $270 \pm 53$ & $52 \pm 44$ & $474 \pm 63$ & $37 \pm 28$ & 26.6 & 21.5 \\
127 & $208 \pm 86$ & n.d. & $349 \pm 134$ & $17 \pm 5$ & 177.2 & 18.8 \\
157 & $130 \pm 4$ & n.d. & $155 \pm 124$ & $22 \pm 25$ & 42.6 & 16.2 \\
\hline
\end{tabular}

a Total rainfall and average soil temperature $(10 \mathrm{~cm})$ for the periods between samplings, data on day 0 is for the period of 7 days preceding application of the treatments.

$\mathrm{b}_{ \pm}$standard deviation.

${ }^{\mathrm{c}}$ n.d. - not detected, limit of detection $=15 \mu \mathrm{g} / \mathrm{kg}$ dry soil.

Temperature had a major significant effect on the degradation rate of terbuthylazine in the controlled environment study (Figure 1a). Terbuthylazine residues disappeared 5 times faster at $30^{\circ} \mathrm{C}$ than at $10^{\circ} \mathrm{C}$. These differences in degradation rates due to temperature are similar in magnitude to those found by Dibbern and Pestemer (1992) and Sahid and Teoh (1994), although the soil types used were quite different. The effect of soil water content on degradation was much weaker than temperature, with only small nonsignificant increases in degradation rates with increasing soil water content (Figure 1b). This result is similar to that found for some other herbicides in this and other soils (James et al. 1995; Rahman et al. 1996).

The half-lives for terbuthylazine (based on first order kinetics) in both the field experiments and controlled environment studies are presented in Tables 2 and 3 along with the $R^{2}$ values for the fitted regressions. The high $R^{2}$ values for the controlled environment studies demonstrated that the degradation of terbuthylazine closely followed first order reaction kinetics. The $\mathrm{R}^{2}$ values for the field degradation are also quite high but suggest slight deviation from a pure first order degradation rate with faster decay in the first 50 days. The half-lives were considerably shorter in the field (Table 2) compared to those in the controlled environments (Table 3) using the same soil. At $10 \mathrm{~cm}$ depth the average field temperatures were considerably less than $30^{\circ} \mathrm{C}$ 
(Table 1). Closer to the surface, the soil temperature could have exceeded $30^{\circ} \mathrm{C}$ for short periods, but this would still not account for the shorter half-life of terbuthylazine in the field. Also, rainfall was not excessive during this period (Table 1) and the herbicide remained close to the surface. Higher levels of microbial activity in the field than in the controlled environment studies could have caused the faster degradation rates in the field. Visser et al. (1984) demonstrated that microbial activity declined with time under laboratory conditions similar to ours, whereas it was stimulated in the field by daily fluctuations of light, temperature and moisture. Photodegradation and volatilisation of the herbicide from the soil surface may also have contributed to the accelerated loss in the field.
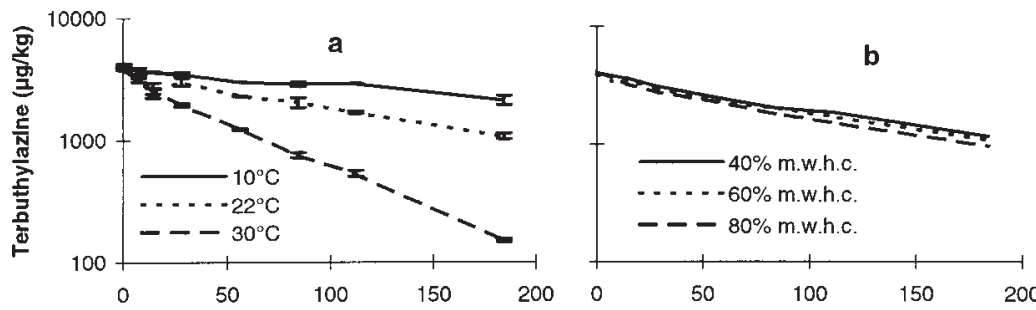

Days after terbuthylazine application to soll

FIGURE 1: Degradation of terbuthylazine under five different temperature and moisture regimes, a, effect of temperature at $60 \%$ m.w.h.c. $( \pm$ standard deviation) and $b$, effect of moisture at $22^{\circ} \mathrm{C}$ (not significantly different).

TABLE 2: Half-life of terbuthylazine (days) under field conditions.

\begin{tabular}{ccc}
\hline Rate $(\mathrm{kg} \mathrm{ai} / \mathrm{ha})$ & Horotiu & Hamilton \\
\hline 1.5 & $23(0.90)^{\mathrm{a}}$ & $39(0.93)$ \\
3.0 & $22(0.91)$ & $34(0.97)$ \\
\hline
\end{tabular}

${ }^{\text {a }} \mathrm{R}^{2}$ value for the regression of the semi-log plot.

TABLE 3: Half-life of terbuthylazine (days) under controlled environment conditions.

\begin{tabular}{cccc}
\hline $\begin{array}{c}\text { Soil moisture } \\
(\% \text { m.w.h.c. })\end{array}$ & \multicolumn{3}{c}{ Temperature $\left({ }^{\circ} \mathrm{C}\right)$} \\
\hline 40 & $-^{\mathrm{a}}$ & $102(0.98)^{\mathrm{b}}$ & - \\
60 & $219(0.95)$ & $99(0.98)$ & $40(0.97)$ \\
80 & - & $89(0.99)$ & - \\
\hline
\end{tabular}

a- not determined.

${ }^{\mathrm{b}} \mathrm{R}^{2}$ value for the regression of the semi-log plot.

The results from the field studies on persistence and the laboratory studies on degradation reported here suggest that, at rates used for selective weed control in arable soils, terbuthylazine would be degraded to low levels within 6 months. This suggests that a progressive build up of residues should not occur with consecutive annual applications of this herbicide. After surface application, terbuthylazine could not be detected below $10 \mathrm{~cm}$ depth indicating a low probability of contaminating the groundwater even where the water table is close to the soil surface. 


\section{ACKNOWLEDGEMENTS}

The authors wish to thank Geoff Wise and Richard Gray for technical help in collecting and processing the soil samples.

\section{REFERENCES}

Barreda de, D.G., Lorenzo, E., Gamon, M., Walker, A., Ramos, C., Saez, A., Carbonell, E.A., Cuadra, J.G. and Lindon, A.L., 1996. Persistence and leaching of some residual herbicides in cropping soils. Bull. Environ. Contamination Toxicol. 56: 219-224.

Bowman, B.T., 1989. Mobility and persistence of the herbicides atrazine, metolachlor and terbuthylazine in Plainfield sand determined by using field lysimeters. Environ. Toxicol. Chem. 8: 485-491.

Dibbern, H. and Pestemer, W., 1992. Application of simulation models for the leaching behaviour of pesticides in soils. Nachrichtenblatt des Deutschen Pflanzenschutzdienstes 44: 134-143.

Dousset, S., Mouvet, C. and Schiavon, M., 1997. Degradation of ${ }^{14}$ C terbuthylazine and ${ }^{14} \mathrm{C}$ atrazine in laboratory soil microcosms. Pestic. Sci. 49: 9-16.

James, T.K., Klaffenbach, P. Holland, P.T. and Rahman, A., 1995. Degradation of primisulfuron-methyl and metsulfuron-methyl in soil. Weed Res. 35: 113-120

Nordmeyer, H. and Pestemer, W. 1995. Laboratory degradation and sorption experiments of pesticides in soil profiles. Z. Kulturtechnik Laudentwicklung 36: 6-10.

Rahman, A., James, T.K., Baskaran, S., Holland, P.T. and Lauren, D.R., 1996. Persistence and degradation of flumetsulam in a New Zealand volcanic soil.Proc. Sec. Int. Weed Control Congress Copenhagen: 281-286.

Rahman, A. and Matthews, L.J. 1979. Effect of soil organic matter on the phytotoxicity of thirteen s-triazine herbicides. Weed Sci. 27: 158-161.

Sahid, I.B. and Teoh, S.S., 1994. Persistence of terbuthylazine in soils. Bull. Environ. Contamination Toxicol. 52: 226-230.

Visser, S., Fujikawa, J., Griffiths, C.L. and Parkinson, D., 1984. Effect of topsoil storage on microbial activity, primary production and decomposition potential. Plant and Soil 122: 41-50. 